\title{
A PRÁTICA COMO COMPONENTE CURRICULAR E OS CONTEÚDOS DA FONÉTICA E FONOLOGIA: UMA DISCUSSÃO A PARTIR DA COMPLEXIDADE
}

\author{
THE PRACTICE AS A CURRICULAR COMPONENT AND \\ THE CONTENTS OF PHONETICS AND PHONOLOGY: A \\ DISCUSSION FROM COMPLEXITY
}

Carine HAUPT ${ }^{1}$

Resumo: O presente trabalho tem como objetivo principal discutir a integração de conhecimentos científicos com a prática como componente curricular a partir da disciplina de Fonética e Fonologia e, por extensão, de outras disciplinas do núcleo duro. A discussão pauta-se na perspectiva da complexidade, compreendendo língua, sala de aula e formação docente como sistemas dinâmicos complexos, ou seja, heterogêneos, não lineares e auto organizáveis na medida em que se coadaptam com outros sistemas. Demonstra-se, primeiramente, a importância da Fonética e Fonologia na formação do professor de Língua Materna, não só para a compreensão da estrutura e funcionamento da língua, mas também para a prática em sala de aula, vinculada a habilidades e conteúdos, como ortografia, expressividade nos gêneros orais e escritos e preconceito linguístico. Situada a Fonética e Fonologia dentro desse imbricado complexo que é a língua e a formação docente e, a partir da leitura de documentos oficiais que pautam sobre a prática como componente curricular, parte-se para a apresentação de uma proposta de projeto dentro dessa perspectiva prática. Constata-se a pertinência de integrar prática aos saberes específicos, uma vez que se extrapola a reprodução fragmentada do conhecimento, promovendo o entendimento da complexidade da realidade.

Palavras-chave: Fonética e Fonologia. Prática como componente curricular. Formação Docente. Complexidade. Sistemas Dinâmicos Complexos.
Abstract: The present work has as main objective to discuss the integration of scientific knowledge with practice as a curricular component from the discipline of phonetics and phonology and, by extension, of other hard core disciplines. The discussion is based on the perspective of complexity, comprising language, classroom and teacher education as complex dynamic systems, that is, heterogeneous, non-linear and self-organizing as they co-adapt with other systems. We demonstrate first the importance of Phonetics and Phonology in the formation of the first language teacher, not only to understand the structure and functioning of the language, but also to practice in the classroom, linked to skills and content such as spelling, expressiveness in oral and written genres, and linguistic prejudice. Phonetics and phonology are located within this imbricated complex, which is the language and teacher education. From the reading of official documents that guide practice as a curricular component, we set out to present a project within this practical perspective. We note the pertinence of integrating practice with specific knowledge, since it extrapolates the fragmented reproduction of knowledge, promoting an understanding of the complexity of reality.

Keywords: Phonetics and phonology. Practice as curricular component. Teacher education. Complexity. Complex Dynamic Systems.

1 Haupt. UFT. E-mail: carineh@uft.edu.br. ORCID ID: https://orcid.org/0000-0002-9471-2265 
- | A prática como componente curricular e os conteúdos da fonética e fonologia: uma discussão a partir da complexidade

\section{Introdução}

A ideia de permear toda a formação inicial de professores pela prática não é nova. No entanto, em documentos oficiais, com fins normativos, a prática veio a configurar parte integrante dos currículos (sem considerar os estágios curriculares) em 2001, no parecer CNE/CP 1/2001. Com o nome de prática de ensino, instituíram-se 400 horas obrigatórias nos currículos. Devido às discussões sobre o que vem a ser prática de ensino e à confusão com estágio supervisionado (questão que não aprofundaremos neste trabalho), ainda em 2001 institui-se o nome prática como componente curricular (PCC) presente no parecer CNE/CP n. 28/2001, e confirmado na resolução CNE/CP 1/2002. Atualmente, com uma nova resolução em vigor (CNE/CP 2/2015), a ideia da PCC continua perfazendo a discussão da formação inicial e continuada dos professores, e junto com ela, apesar do tempo de vigência, ainda persistem muitas dúvidas de como inserir esse componente nos projetos políticos pedagógicos dos cursos de licenciatura. O que tem se observado, em muitos casos, é a inserção de carga horária prática distribuída nas disciplinas específicas e, em alguns casos, confusão entre a prática que se configura como conhecimento técnicocientífico e a prática voltada para a docência.

Essas prerrogativas legais visam oferecer uma formação mais ampla ao docente, com conhecimentos que extrapolem a sala de aula e integrem, de maneira mais eficiente, a teoria e a prática, além de abarcar outras nuances do fazer docente que vão além do conhecimento teórico e pedagógico. É, portanto, compatível com a perspectiva de cunho emergentista que adotamos nesta discussão: o pensamento complexo. "A complexidade compreende, efetivamente, o tecido de acontecimentos, ações, interações, retroações, determinações, acasos que constituem o nosso mundo fenomenal" (MORIN, 1990, p. 20). Trata-se, como veremos em maiores detalhes a seguir, de uma perspectiva alternativa ao cartesianismo, uma abordagem dinâmica da constituição do conhecimento.

É nesse contexto que inserimos a nossa discussão, partindo de uma pergunta central: como os professores de áreas tradicionalmente conhecidas como sendo do núcleo duro da Linguística podem pensar a prática como componente curricular? O nosso enfoque será voltado para a disciplina de Fonética e Fonologia, no entanto, acreditamos que as conclusões podem ser generalizadas para outras disciplinas, tais como, Morfologia, Sintaxe e Semântica, por exemplo. Os objetivos deste texto, portanto, são: i) evidenciar a importância da disciplina de Fonética e Fonologia para a formação do professor de Língua Materna (LM) a partir da compreensão de sistemas complexos e dinâmicos, ii) mostrar possíveis caminhos para a inserção da PCC em Fonética e Fonologia; iii) refletir sobre a pertinência da PCC integrada a conhecimentos específicos para a formação do professor 
de LM, compreendendo a língua como sistema complexo. Com essa discussão, buscamos contribuir para a ressignificação do ensino de conteúdos específicos na área da Teoria e Análise Linguística, de modo que possam integrar as competências e habilidades exigidas do profissional de Letras na Educação Básica na atualidade.

Para contemplar esses objetivos, dividimos o texto em duas seções, além desta introdução e das considerações finais. Na primeira, procuramos demonstrar a importância e pertinência da Fonética e Fonologia como parte da formação do professor de LM. Pensamos nessa inserção a partir de concepção de sistemas complexos. Também verificamos na Base Nacional Comum Curricular do Ensino Fundamental (MEC, 2018) menções a tópicos que remetam para conhecimentos e habilidades que se relacionam com a Fonética e a Fonologia, a fim de apresentar alguns exemplos de como os conhecimentos em Fonética e Fonologia podem ser vinculados a conteúdos diversos no Ensino Básico. Na segunda seção, adentramos a discussão legal, apresentando excertos da CNE/CP 02/2015, a fim de discutir a noção de PCC e como ela pode ser inserida ou vinculada à disciplina de Fonética e Fonologia, a partir do relato de um projeto realizado com uma turma da disciplina de Introdução à Fonética e Fonologia do curso de Letras, da Universidade Federal do Tocantins, campus de Porto Nacional. O elo entre as duas seções se estabelece, uma vez que a PCC pode ser vista como meio de efetivar a aprendizagem na disciplina de Fonética e Fonologia, que, segundo alguns estudos (CARVALHO, 2014; SOUZA, 2014) não tem acontecido e, tampouco, a ligação entre teoria e futura prática docente.

\section{A Fonética e Fonologia na formação do professor de LM na perspectiva da complexidade}

Fonética e Fonologia é uma disciplina comumente oferecida no início do curso de licenciatura em Letras. O que tem se observado é que os conteúdos discutidos nessa disciplina são desvinculados da prática docente, ou seja, os futuros professores não conseguem estabelecer uma ponte entre esse conhecimento e o fazer docente na Educação Básica. Alguns trabalhos atestam, inclusive, que pouco do que se estudou fica como conhecimento efetivo para os formandos. Muito se esquece ou não se compreende. É o que mostra o trabalho de Carvalho (2012), no qual a autora faz um questionário com alunos formandos acerca dessa disciplina. Como conclusão, ela afirma:

Pode-se declarar textualmente pela experiência que se tem com a disciplina e pelas respostas apontadas que as dificuldades nessa área de conhecimento se dão por inúmeros fatores, conforme eles já elencaram, tais como, falta de 
- A prática como componente curricular e os conteúdos da fonética e fonologia: uma discussão a partir da complexidade

base no ensino regular (fundamental e médio), pouca atenção e tempo (carga horária) dados aos conteúdos, falta de aprofundamento dos conteúdos, visto que alguns são discutidos superficialmente. Acrescente-se aí que essa disciplina não somente nessa Instituição de Ensino como em outras tanto públicas como privadas é pouco valorizada, a começar pela carga horária destinada a ela, com exceção de algumas que acrescentam no currículo a disciplina Fonética acústica, além da articulatória, mas em grande parte como disciplina optativa. (CARVALHO, 2012, p. 17).

Diante dessa contextualização, entendemos que é preciso, em primeiro lugar, estabelecer a importância dessa disciplina na formação do professor de LM. Para tanto, é necessário que tenhamos a compreensão de que a língua assim como a formação do professor e a sala de aula são sistemas dinâmicos complexos. Aqui não compreendemos sistema como uma estrutura acabada em si, como se pregava no Estruturalismo, por exemplo. Num viés complexo, um sistema está em constante processo organizativo "no fluxo contínuo de desequilíbrio, organização/reorganização, equilíbrio, etc., mudando sempre, mas mantendo sua identidade em 'estados de equilíbrio'" (NASCIMENTO, 2011, p. 62).

Surgida inicialmente nas ciências naturais, a teoria da complexidade tem sido cada vez mais utilizada para a compreensão de sistemas humanos e sociais. Como destaca Morin (1990), a vida humana é um fenômeno de autoeco-organização extraordinariamente complexo e, portanto, os fenômenos antropossociais não podem obedecer a princípios de inteligibilidade menos complexos do que aqueles requeridos para os fenômenos naturais. (MARTINS; BRAGA, 2007, p. 215).

Compactuado com esse ponto de vista, delineamos as características de um sistema dinâmico complexo para verificar como a língua, o aluno em formação docente inicial e sala de aula podem ser compreendidos como tais. Segundo Morin (2013, p. 128), "nosso mundo organizado é um arquipélago de sistemas no oceano da desordem" e "todo sistema integra e organiza a diversidade numa unidade". Isso significa dizer que a complexidade, a desordem (ou o caos) são parte integrante aos sistemas. Estes, por sua vez, caracterizam-se como abertos, pois "permitem que energia ou matéria externa entre no sistema. Essa abertura permite que um sistema distante do equilíbrio esteja em constante adaptação, mantendo sua estabilidade" (LARSEN-FREEMAN; CAMARON, 2008, p. 32). Assim, prevê-se a interrelação entre diferentes sistemas. 
Os sistemas complexos são, portanto, heterogêneos, constituídos de diferentes componentes e agentes. São sensíveis às condições iniciais, pequenas mudanças em um estado inicial podem criar efeitos de dimensões imprevisíveis (a relação entre os componentes não é simétrica). São também contextualizados, relacionam-se com outros sistemas, como em um ecossistema. São coadaptivos, respondem e influenciam mudanças em outros sistemas. E, por fim, são auto-organizáveis, porque, a despeito da aparente desordem dos padrões de interação de seus componentes, a ordem emerge (FERYOC, 2010).

Assim, compreendemos que a língua é heterogênea, constituída de falantes (agentes) e componentes (léxico, regras pragmáticas, outros sistemas, ou subsistemas fonético-fonológico ${ }^{2}$, morfológico, sintático, semântico...). Esses subsistemas relacionamse entre si, isto é, uma mudança que ocorre no nível fonológico pode atingir outro subsistema, como o semântico, por exemplo. No entanto, não é possível prever com exatidão o impacto que uma mudança vai ter no sistema como um todo, ou mesmo se ela vai conseguir se fixar, porque não há simetria entre causa e efeito. A implementação vai depender do feedback (ou retroalimentação), princípio fundamental que explica os momentos de caos e estabilidade nos sistemas, ou seja, a sua auto-organização (OLIVEIRA, 2016). A retroalimentação consiste na utilização do output de um sistema para realimentar seu próprio input. É o que acontece quando uma forma emergente surge da interação de um número limitado de falantes e espalha-se por cada vez mais falantes.

A retroalimentação pode acontecer entre elementos internos ao sistema ou com elementos dos ambientes, ou seja, de outros sistemas. Isso equivale a dizer que a língua é influenciada e influencia outros sistemas, externos a si mesma. Dessa forma, podemos afirmar que ela é dinâmica, com processos de auto-organização decorrentes da coadaptação das mudanças que ocorrem dentro e fora dela. Entender a língua nesses termos significa dizer que ela é um todo no qual as partes interagem constantemente entre si e com o ambiente. Fica, então, evidente que o componente fonético-fonológico é parte desse sistema e que, ao se debruçar sobre ele, deve-se levar em conta as interações com os outros subsistemas e ainda com outros sistemas, como a sala de aula, já que estamos tratando de um curso de licenciatura. Isso implica a relação entre teoria e prática. É o que preconiza a CNE/CP 2/2015:

2 Utilizamos o termo fonético-fonológico, pois pautamos nossa concepção em uma Fonologia dinâmica, na qual o fone é evidência para as distinções funcionais da Fonologia, sem que haja a tradicional dicotomia entre Fonética e Fonologia. 
- A prática como componente curricular e os conteúdos da fonética e fonologia: uma discussão a partir da complexidade

É preciso indicar com clareza para o aluno qual a relação entre o que está aprendendo na licenciatura e o currículo que ensinará no segundo segmento do ensino fundamental e médio. Neste segundo caso é preciso identificar, entre outros aspectos, obstáculos epistemológicos, obstáculos didáticos, relação desses conteúdos com o mundo real, sua aplicação em outras disciplinas, sua inserção histórica. Esses dois níveis de apropriação do conteúdo devem estar presentes na formação do professor. (CNE/CP, 2002, p. 21).

É possível identificarmos, a partir dessa citação, um outro sistema complexo, ou, de acordo com a concepção de De Bot, Lowie e Vespoor (2007), um subsistema dinâmico dentro de um sistema social: o aluno em formação docente inicial. Como tal, ele interage com o sistema que está aprendendo - a língua - em meio a uma realidade social e histórica, tanto pessoal quanto coletiva, fatores que influenciam o sistema, forçando-o a se coadaptar. Segundo Perozzo e Alves (2013), ele é constituído de um ecossistema cognitivo (cognição, inteligência, motivação, aptidão) e um ecossistema social (linguagem, nível de escolaridade, poder aquisitivo) ambos interligados e imbuídos de inúmeras variáveis.

Durante o percurso, surgem períodos de caos, de turbulência, para uma consequente reorganização. Pensemos nisso a partir de uma aula teórica de Fonética e Fonologia: é muito comum o aluno chegar à graduação dizendo que no português há cinco vogais. Ao receber a informação de que são sete (orais, no caso), cria-se um momento de instabilidade, necessário para que o aluno reorganize seu sistema, integrando a ele uma nova concepção de vogal, que não corresponde àquela associada às letras "a, e, i, o, u". No entanto, é possível que esse novo estado não se efetive no sistema, e o aluno continue assumindo apenas cinco vogais, pois são muitas as variáveis que envolvem o processo de aprendizagem e o próprio aluno em formação.

Ao voltar o conhecimento teórico construído em uma disciplina como Fonética e Fonologia para a prática docente, é importante que o aluno compreenda que a sala de aula é outro sistema complexo, no qual diferentes agentes (aluno, professor, diretor, pais...), cada qual também um sistema complexo (ou subsistema dentro de um sistema social maior), e componentes (o ambiente físico, por exemplo) são elementos que interferirão na sua prática. Isso significa dizer que não basta ter domínio teórico da língua que vai ensinar: "é preciso identificar, entre outros aspectos, obstáculos epistemológicos, obstáculos didáticos, relação desses conteúdos com o mundo real, sua aplicação em outras disciplinas, sua inserção histórica" (CNE/CP, 2002, p. 21). É uma rede complexa de conexões, na qual temos uma "previsibilidade limitada: o processo global de aprendizagem segue uma direção mais ou menos previsível e alguns estados 'atratores' do 
processo podem ser presumidos, mas avanços específicos na aprendizagem só podem ser definidos de forma parcial e temporária" (FLEISCHER, 2011, p. 81).

A noção de atratores é central numa teoria de sistemas dinâmicos complexos. Atratores são estados para os quais o sistema tende a ir, se estabilizar. Por exemplo, ao aprender Inglês enquanto falante do Português, o sistema da interlíngua tenderá para algumas pronúncias pertencentes aos padrões do Português, como a inserção de epêntese em consoantes finais. Essas pronúncias constituem o espaço fase disponível no sistema naquele momento. À medida que o sistema vai sendo alimentado (aulas, exercícios, leituras), instabilidades vão se formando, novos atratores serão inseridos nos espaços de fase, moldando-os, até que a pronúncia convirja para um novo atrator, próprio da língua alvo, que é a pronúncia da consoante final sem a epêntese.

Fica evidente o grande desafio que é o processo de ensino-aprendizagem. Acreditamos que uma das grandes dificuldades do ensino da LM reside justamente na dificuldade de relacionar os conteúdos teóricos com a prática docente. Nesse sentido, uma abordagem puramente linguística não é o suficiente. Voltemos então à Fonética e Fonologia, tentando evidenciar de que maneira ela pode ser inserida na prática docente. Para tanto, comecemos com a BNCC (Base Nacional Comum Curricular). Ao lermos a BNCC do Ensino Fundamental, percebemos que, embora ela não tenha como fundamentação teórica explícita o paradigma da complexidade e os sistemas dinâmicos complexos, é possível ver que o tratamento dado ao ensino da língua e à compreensão de linguagem está de acordo com essa perspectiva:

Um exemplo dessas proposições pode ser visto na ênfase dada pela BNCC ao exame do caráter histórico e contextual das práticas de linguagem, de modo a permitir o entendimento das razões do seu uso, da valoração, da representatividade, dos interesses sociais colocados em jogo e das escolhas de atribuição de sentidos, ou seja, a consciência do poder constitutivo da linguagem. Destaca-se que a própria linguagem é objeto de reflexão e análise, permitindo aos alunos a compreensão e a transformação do próprio objeto de estudo. (MEC, 2018, p. 60).

Vemos, portanto, que a língua e outras manifestações de linguagem estão inseridas em sistemas sociais e históricos, todos em interação. Do mesmo modo, o próprio aluno, enquanto agente, interage e transforma o sistema, o que configura a auto-organização. Por outro lado, a linguagem (e língua) também fazem parte do sistema complexo que é o aluno (ou os indivíduos de forma geral) e é mais um elemento de sua constituição. A partir dessa concepção, a proposta de ensino de Língua Materna pauta-se nas práticas de linguagens 
- A prática como componente curricular e os conteúdos da fonética e fonologia: uma discussão a partir da complexidade

a partir de cinco eixos: a escrita, a oralidade, a leitura, os conhecimentos linguísticos e gramaticais e a educação literária. À primeira vista, parece óbvio que a Fonética e Fonologia inserem-se no eixo conhecimentos linguísticos e gramaticais, no entanto, veremos a partir de alguns exemplos que ela pode permear todos os eixos. O excerto a seguir evidencia como todos esses eixos estão integrados, configurando, mais uma vez, a complexidade do sistema linguístico. A primeira constatação é de que a língua tem duas dimensões. No decorrer da leitura, evidencia-se que os conhecimentos linguísticos e gramaticais, assim como a educação literária, estão para desenvolver habilidades de uso da língua nessas duas dimensões, conforme grifo nosso na citação:

A língua tem duas dimensões: é oral e escrita. Assim, sua aprendizagem considera o contínuo entre oralidade e escrita: na alfabetização, em que o oral é representado por notações (letras e outros signos), nos usos sociais da língua oral e nos usos sociais da leitura e da escrita nas práticas de letramento. A meta do trabalho com a Língua Portuguesa, ao longo do Ensino Fundamental, é a de que crianças, adolescentes, jovens e adultos aprendam a ler e desenvolvam a escuta, construindo sentidos coerentes para textos orais e escritos; a escrever e a falar, produzindo textos adequados a situações de interação diversas; a apropriar-se de conhecimentos e recursos linguísticos textuais, discursivos, expressivos e estéticos - que contribuam para o uso adequado da língua oral e da língua escrita na diversidade das situações comunicativas de que participam. (MEC, 2018, p. 62, grifo nosso).

A partir dessa citação, vemos apontadas três possibilidades de vincular os conhecimentos de Fonética e Fonologia para o desenvolvimento de diferentes habilidades em diferentes eixos no Ensino Fundamental'3 . São elas: a variação linguística, uma vez que o aluno deve usar a língua adequadamente em diferentes situações comunicativas; estudo de recursos sonoros em diferentes gêneros textuais, tanto orais quanto escritos e também literários (atrelando-os aos efeitos de sentido na comunicação) e o estudo da ortografia, voltado mais especificamente para o eixo da escrita. Abaixo apresentamos um exemplo de exploração de elementos de sonoridade para a atribuição de sentidos, muito presente em textos literários (mas que também pode constituir outros gêneros): a aliteração. Tratase de um conhecimento linguístico-gramatical, no nível fonético-fonológico, que se configura como estratégia para o desenvolvimento produtivo da prática de leitura, nesse caso em específico:

3 A questão da relevância de se ensinar conteúdo específico de Fonética e Fonologia nesse nível de ensino não será discutida neste trabalho. 
Quadro 1. Exemplo de atividade

Leia o seguinte verso de Fernando Pessoa:

Um copo cheio de sanguessugas, a sugar, a sugar.

Explique a expressividade conferida ao verso através da aliteração.

Fonte: Rodrigues (2005, p. 18)

A Fonética e a Fonologia são ainda um subsídio para o estudo da variação linguística. Isso pode ser feito através da identificação de fenômenos de variedade Fonética (como a palatalização, assimilação, etc.) e da identificação de elementos prosódicos que caracterizam diferentes falares; da análise das diferenças entre oralidade e escrita; e, por fim, a partir da discussão acerca do preconceito linguístico, considerando não somente as variedades Fonéticas, mas todas as marcas que estigmatizam um determinado falar. Desse modo, Fonética e Fonologia integram-se às habilidades, elencadas na BNCC, de

[...] justificar fatores determinantes de registro linguístico (formal, informal), como: contexto, ambiente, tema, estado emocional do falante, grau de intimidade entre os falantes; adequar o nível de formalidade da fala aos temas, contextos/situações, interlocutores; reconhecer a manifestação de preconceitos linguísticos como formas de discriminação e dominação; respeitar a variação linguística por características sociais, regionais, urbanas e rurais da fala, rejeitando preconceitos linguísticos. (MEC, 2018, p. 116).

Em relação à norma ortográfica, os conhecimentos de Fonética e Fonologia são essenciais para compreender a relação entre grafema (letras) e som (fonema/fone), especialmente para entender as regularidades da norma. A norma ortográfica é uma convenção social, mas é possível estabelecer relações entre o som e sua representação gráfica. Morais (2007) divide essas relações em três tipos: as regularidades diretas (aquelas em que há um grafema para cada som, ou seja, a relação é biunívoca); regularidades dependentes de contexto (aquelas em que o contexto em que o som está inserido será determinante para a escolha de um grafema específico, isto é, trata-se de uma regra fixa, previsível); e as irregularidades (aquelas em que temos mais de um grafema para representar um mesmo som, sem que seja possível prevê-lo a partir do contexto, exemplo mais notório no português são as inúmeras representações para o fonema /s/).

Citamos brevemente duas regularidades contextuais para exemplificação. No primeiro caso, temos uma regra de decodificação. A pronúncia do grafema "g" é previsível 
- | A prática como componente curricular e os conteúdos da fonética e fonologia: uma discussão a partir da complexidade

de acordo com o contexto seguinte, se vogal anterior ou posterior e baixa. No segundo, mostramos um exemplo de codificação. Neste é imprescindível ter ainda conhecimento sobre as variedades, uma vez que essa regra pode não se aplicar em determinadas localidades.

- O grafema "g" com vogais anteriores $[i, e, \varepsilon]$ corresponde à transcrição do fonema /3/; com as posteriores e a baixa, à transcrição do fonema /g/;

- O fonema /i/ em final de palavras pode ser transcrito com o grafema "e" ou "i": quando a sílaba for átona, transcreve-se com a letra " $\mathrm{e}$ ", quando for tônica, com a letra "i" (ou "-ir", no caso dos verbos no infinitivo - regra contextual de caráter fonomorfológico (SCLIAR-CABRAL, 2003)).

Assim, fica evidente que a Fonética e Fonologia interagem com outros sistemas (ou partes deles): na constituição de gêneros textuais; nas manifestações culturais; na aprendizagem da escrita; na identidade linguística dos falantes, dentre outros. Ao mesmo tempo, na medida em que interage, sofre também alterações, motivo pelo qual evidenciamos variações e mudanças no nível fonético-fonológico. A partir da compreensão da teoria de sistemas complexos e dinâmicos, se "reconhece e equipara, em termos de influência no sistema, variáveis linguísticas, sociais, cognitivas e comportamentais" (PEROZZO; ALVES, 2013), o que faz dessa teoria um modelo mais coerente para a descrição da realidade.

\section{A prática como componente curricular (PCC) e a Fonética e a Fonologia}

Com a clareza de que a Língua, assim como seu ensino, são sistemas complexos; de que a Fonologia é um subsistema que interage com elementos dentro da própria língua e fora dela; e de que os egressos dos cursos de formação têm dificuldades em lidar com os conhecimentos teóricos discutidos durante o curso, voltamo-nos agora para a discussão da PCC. A primeira distinção que deve ser feita é entre o que significa prática e prática como componente curricular (PCC) dentro dos documentos oficiais. Vejamos o excerto a seguir:

[...] a prática como componente curricular é o conjunto de atividades formativas que proporcionam experiências de aplicação de conhecimentos ou de desenvolvimento de procedimentos próprios ao exercício da docência. Por meio destas atividades, são colocados em uso, no âmbito do ensino, os conhecimentos, as competências e as habilidades adquiridos nas diversas atividades formativas que compõem o currículo do curso. As 
atividades caracterizadas como prática como componente curricular podem ser desenvolvidas como núcleo ou como parte de disciplinas ou de outras atividades formativas. Isto inclui as disciplinas de caráter prático relacionadas à formação pedagógica, mas não aquelas relacionadas aos fundamentos técnicocientíficos correspondentes a uma determinada área do conhecimento. [...] (CNE/CP, 2015, p. 32).

Como vemos, a PCC não está incluída em disciplinas relacionadas aos fundamentos técnico-científicos. Isso não significa dizer que não há prática nessas disciplinas. Em uma disciplina como Fonética e Fonologia temos atividades práticas, como, por exemplo, coletar dados, através de uma entrevista, e depois fazer a transcrição Fonética. No entanto, essa prática não se configura como PCC, pois não está voltada para a docência, mas sim para o conhecimento científico específico. A PCC tem como pré-requisito estar direcionada para a docência. Em maiores detalhes a seguir:

A prática como componente curricular é, pois, uma prática que produz algo no âmbito do ensino. Sendo a prática um trabalho consciente [...]. Em articulação intrínseca com o estágio supervisionado e com as atividades de trabalho acadêmico, ela concorre conjuntamente para a formação da identidade do professor como educador.

Esta correlação teoria e prática é um movimento contínuo entre saber e fazer na busca de significados na gestão, administração e resolução de situações próprias do ambiente da educação escolar.

A prática, como componente curricular, que terá necessariamente a marca dos projetos pedagógicos das instituições formadoras, ao transcender a sala de aula para o conjunto do ambiente escolar e da própria educação escolar, pode envolver uma articulação com os órgãos normativos e com os órgãos executivos dos sistemas. Com isto se pode ver nas políticas educacionais e na normatização das leis uma concepção de governo ou de Estado em ação. Podese assinalar também uma presença junto a agências educacionais não escolares tal como está definida no Art. $1^{\circ}$ da LDB. Professores são ligados a entidades de representação profissional cuja existência e legislação eles devem conhecer previamente. Importante também é o conhecimento de famílias de estudantes sob vários pontos de vista, pois eles propiciam um melhor conhecimento do ethos dos alunos. (CNE/CP, 2015, p. 31). 
- | A prática como componente curricular e os conteúdos da fonética e fonologia: uma discussão a partir da complexidade

Embora o documento seja direcionado para orientar a facção de projetos políticos pedagógicos de curso, é possível estabelecermos pontes com a nossa área. Em primeiro lugar, fica expresso que essa articulação entre teoria e prática deve se dar desde o início do processo de formação e percorrer todo o curso. Assim, como a Fonética e Fonologia estão normalmente no início do curso, é pertinente já pensar como essa disciplina pode contribuir para a formação do professor. Uma leitura possível é pensar que a PCC estaria melhor vinculada a disciplinas pedagógicas, ou a disciplinas específicas para essa prática, e de que as disciplinas de conhecimentos técnico-científicos não se prestariam a essa função. Pensamos, no entanto, que há meios sim de incluir essas disciplinas em projetos que possam se configurar como PCC. Afinal, ao realizar um projeto que relaciona teoria e prática, múltiplos saberes devem ser mobilizados, incluindo conhecimentos técnicos e científicos, pois como diz o parecer, "a prática deve [...] dar conta dos múltiplos modos de ser da atividade acadêmico-científica" (CNE/CP, 2015, p. 31). Esses projetos podem ser desenvolvidos no decorrer da disciplina ou em um momento à parte, específico para a PCC, a depender do projeto político pedagógico de cada curso.

Outro ponto que achamos pertinente no excerto acima é de que a PCC extrapola a sala de aula, tanto da universidade quanto do Ensino Básico. Busca-se uma formação mais ampla, um professor capaz de entender o quadro todo que subjaz ao sistema da Educação. E ainda, que conheça também a comunidade em que está inserida a escola: "Importante também é o conhecimento de famílias de estudantes sob vários pontos de vista, pois eles propiciam um melhor conhecimento do ethos dos alunos" (CNE/CP, 2015, p. 31). A proposta é muito interessante e compatível com a perspectiva da complexidade adotada nesta discussão, pois vislumbra-se uma formação voltada para o fazer docente como um todo, no qual elementos e agentes interagem. Nesse viés, apresentamos a seguir a proposta de um projeto de PCC, envolvendo a Fonética e Fonologia, levando o aluno a conhecer a comunidade escolar de seu bairro de residência, realizada com uma turma no curso de Letras. 
Quadro 2. Proposta de projeto de PCC, envolvendo Fonética e Fonologia

\section{Objetivos:}

- Despertar os alunos para as especificidades da variedade do português falado da comunidade em que reside a partir da audição de vários discursos orais espontâneos;

- Instrumentalizar os alunos com subsídios teóricos e práticos para se posicionar diante de situações que envolvam preconceito linguístico na escola.

O aluno, ao final do projeto, deverá ser capaz de:

- Identificar marcas Fonéticas/fonológicas típicas da comunidade escolar investigada;

- Comparar diferentes variedades linguísticas em relação a diferentes fenômenos fonéticos/ fonológicos, como, por exemplo, a ditongação e o rotacismo;

- Discutir acerca do preconceito linguístico, considerando que alguns fenômenos são estigmatizados e outros, não;

- Posicionar-se diante de situações de bullying na escola que envolvam questões de linguagem.

\section{Procedimentos:}

Etapa 1: Coleta de dados

Divisão da turma em pequenos grupos, de acordo com proximidade de moradia. Cada aluno fará duas entrevistas com estudantes do Ensino Básico de sua comunidade, preferencialmente a partir do oitavo ano. Essa entrevista deverá ser a mais espontânea possível, uma conversa sobre a escola, os hobbies, a rotina do aluno, ou ainda, a narração de uma história pessoal. O tempo mínimo exigido será de 15 minutos. Os recursos a serem utilizados serão os próprios celulares dos alunos, ou gravadores de MP3.

Etapa 2: Transcrição dos dados

Transcrição grafêmica com aproximação Fonética das entrevistas. Essa transcrição deverá ser digital para que possa ser enviada para os demais grupos. Os símbolos fonéticos deverão ser usados para identificar algum fenômeno que não será possível de ser marcado através da transcrição grafêmica, como, por exemplo, a palatalização da fricativa final, ou a pronúncia da letra " $r$ " em final de sílaba. O professor orientará os alunos para que prestem atenção aos detalhes fonéticos, mas que também não percam de vista outras variações, de outros níveis, como o uso de gírias, ou a ausência de concordância padrão. 
- A prática como componente curricular e os conteúdos da fonética e fonologia: uma discussão a partir da complexidade

Etapa 3: Descrição dos dados

Levantamento dos fenômenos que chamam atenção, ou por serem diferentes de sua variedade, ou por estarem destoantes da norma padrão. Em seguida, fará um levantamento das variações de cunho fonético. Ainda nessa etapa, cada grupo fará a socialização do seu levantamento com os demais grupos para se iniciar um debate, apontando diferenças e semelhanças entre as entrevistas.

Etapa 4: Análise dos dados

Debate sobre as variedades, principalmente, mas não exclusivamente, as Fonéticas. O professor guiará a discussão de modo que os alunos percebam como essas variedades se inserem na comunidade local e dentro da língua, considerando não somente fatores linguísticos, mas também extralinguísticos. Nesse momento, os alunos poderão falar também de suas experiências com o uso da língua na escola.

Etapa 5: Atividade para reflexão

Simulação de uma situação de bullying na escola (os personagens, portanto, serão dois alunos e um professor). A situação deverá ser baseada na variedade linguística dos dados coletados. O foco deverá recair sobre a atitude do professor. Após a apresentação, encerra-se o projeto, propondo-se a escrita de um texto reflexivo sobre o tema e as atividades desenvolvidas.

\section{Fonte: Elaboração própria}

Como é possível ver nessa proposta, não limitamos o olhar do aluno apenas para as variedades Fonéticas. No entanto, lembramos que se trata de um projeto proposto no início do curso, num momento em que o aluno terá alguma bagagem teórica em Fonética e Fonologia, mas não nas demais disciplinas. Mesmo que o aluno ainda não consiga discutir em termos metalinguísticos variações de outros níveis que não as fonético-fonológicas, ele é capaz de percebê-las no discurso do outro, afinal, é falante da língua. É também uma forma de evidenciar que a língua é complexa, composta de diferentes níveis, além de variável. E nada impede que o projeto possa ser ampliado ou aplicado em outro momento do curso, talvez até quando os alunos já estiverem inseridos nos estágios supervisionados.

Muitas outras atividades podem ser pensadas dentro do viés da PCC, incluindo outros níveis de análise linguística, por exemplo, a Morfologia e a Sintaxe. Queremos aqui frisar a pertinência desse tipo de projeto para a formação do professor de LM. Retomamos a constatação apontada no início deste texto, a de que os alunos não conseguem vincular teoria e prática em disciplinas como Fonética e Fonologia. Acreditamos que a PCC se 
traduz em um espaço profícuo para, senão sanar, pelo menos diminuir esse problema. Consequentemente, acreditamos também que a teoria e o conhecimento técnicocientífico, muitas vezes, enfadonhos para os alunos, tornem-se mais significativos. Em termos de teoria de sistemas complexos e dinâmicos, hipotetizamos que as atividades de PCC possam configurar novos espaços fase, nos quais novos atratores serão preferidos, tanto no sistema da língua, quanto do docente em formação, resultando na reorganização desses sistemas, ou seja, na mudança decorrente da aprendizagem, um processo que está em contínuo estado de transformação e reconstrução.

\section{Considerações finais}

A proposta deste texto foi fazer uma reflexão sobre a Fonética e Fonologia na formação do professor de LM. Fizemos essa reflexão pautados na teoria dos sistemas dinâmicos complexos. Defendemos que ela oferece vantagens em relação a outras teorias de língua e de aprendizagem, primeiramente, porque nos permite descrever a realidade como complexa e dinâmica, como é de fato; e, quando pensamos especificamente na formação docente, nos permite abordar a aquisição do conhecimento como processo em incessante evolução.

Não podemos, pois, perder de vista que é característica inerente aos sistemas complexos serem dinâmicos, assim sua evolução é inevitável. Mas nem por isso, podemos deixar ao acaso o docente em formação. Assim, ao inserirmos a prática, não pensando somente no conteúdo científico da disciplina, mas também na formação do docente, permitimos a troca de energia entre sistemas, promovendo momentos de turbulência, de caos, necessários para que o sistema se reorganize e se coadapte. A apresentação de conteúdos de forma fragmentada e desconexa do fazer docente pode não ser energia suficiente para mudar estados de fase e, assim, corremos o risco de reproduzir modelos ineficientes do ensino de LM. Nesta trama complexa que é a formação do professor de LM, vincular teoria e prática, não somente no sentido de lecionar conteúdos, mas também de integrar saberes pedagógicos e contextuais, condiz com a condição de que a escola está inserida em um sistema social complexo, no qual o professor vai ser mais um agente.

\section{Referências}

CARVALHO, L. da S. O ensino de Fonética e Fonologia no curso de Letras/Português. uma experiência com alunos da Universidade Estadual do Piauí - UESPI. Anais do SIELP. v. 2, n. 1. Uberlândia: EDUFU, 2012. 
- | A prática como componente curricular e os conteúdos da fonética e fonologia: uma discussão a partir da complexidade

CARVALHO, L. da S. Reflexões sobre o ensino de Fonética e Fonologia no curso de Letras/Português da Universidade Estadual do Piauí. Interfaces: ensino, educação e tecnologia, Universidade Aberta do Brasil, v. 1, n. 1, p. 1-16, 2014.

CONSELHO NACIONAL DE EDUCAÇÃO/CONSELHO PLENO - CNE/CP. Resolução CNE/CP n. 1, de 18 de fevereiro de 2002. Disponível em: http:/ / portal.mec.gov.br/ seesp/arquivos/pdf/res1_2.pdf. Acesso em: 29 ago. 2018.

\section{CONSELHO NACIONAL DE EDUCAÇÃO/CONSELHO PLENO - CNE/CP. Resolução} CNE/CP n. 2, de 15 de julho de 2015. Disponível em: http://portal.mec.gov.br/cne/ arquivos/pdf/CP022002.pdf. Acesso em: 29 ago. 2018.

DE BOT, K.; LOWIE, W.; VERSPOOR, M. H. A dynamic systems theory approach to second language acquisition. Bilingualism: Language and Cognition, v. 10, n. 1, p. 7-21, 2007.

FERYOC, A. Language teacher cognition: Complex dynamic system? System, University of Otago, New Zealand, v. 38, p. 272-279, 2010.

FLEISCHER, E. Caos/complexidade na interação humana. In: PAIVA, V. L. M. O.;

NASCIMENTO, M. (org.). Sistemas adaptativos complexos: lingua(gem) e aprendizagem. Campinas: Pontes, 2011.

LARSEN-FREEMAN, D.; CAMARON, L. Complex systems and Applied Linguistic. Oxford: Oxford University Press, 2008.

MARTINS, A. C. S.; BRAGA, J. C. F. Caos, complexidade e Linguística Aplicada: diálogos transdisciplinares. Revista Brasileira de Linguística Aplicada. v. 7, n. 2, p. 215-235, 2007.

MINISTÉRIO DA EDUCAÇÃO E CULTURA - MEC. Base Nacional Comum Curricular Educação é a base, 2018. Disponível em: http://basenacionalcomum.mec.gov.br/wpcontent/uploads/2018/06/BNCC_El_EF_110518_versaofinal_site.pdf. Acesso em: 29 set. 2018.

MORAIS, A. G. A norma ortográfica do português: o que é? Para que serve? Como está organizada? In: SILVA, A.; MORAIS, A. G.; MELO, K. L. R. (org.). A ortografia na sala de aula. Belo Horizonte: Autêntica, 2007. 
MORIN, E. Introdução ao pensamento complexo. Lisboa: Instituto Piaget, 1990.

MORIN, E. O método 1: a natureza da natureza. 2. ed. Porto Alegre: Sulina, 2003.

NASCIMENTO, M. do. Linguagem como sistema complexo: interfases e interfaces. In: PAIVA, V. L. M. O.; NASCIMENTO, M. (org.). Sistemas adaptativos complexos: lingua(gem) e aprendizagem. Campinas: Pontes, 2011.

OLIVEIRA, M. A. A auto-organização como mecanismo para a resolução da variação.

Cadernos de Estudos Linguísticos, Campinas, v. 58, n. 3, p. 1-17, set./dez. 2016.

PEROZZO, R. V.; ALVES, U. K. Implicações dinâmicas para a formação da Fonologia em L2. Signo, Santa Cruz, v. 38, n. 65, p. 247-260, jul./dez. 2013.

RODRIGUES, S. V. Fonética e Fonologia no ensino de língua materna: modos de operacionalização. Encontro sobre terminologia linguística: da teoria às práticas. Porto: Faculdade de Letras da Universidade do Porto, 2005.

SCLIAR-CABRAL, L. Princípios do sistema alfabético do Português do Brasil. São Paulo: Contexto, 2003.

SOUZA, J. de S. A Fonética e a Fonologia no currículo do ensino fundamental. XVII Congresso Internacional Asociación de Linguística y Filologia de America Latina. João Pessoa, 2014.

COMO CITAR ESTE ARTIGO: HAUPT, Carine. A prática como componente curricular e os conteúdos da fonética e fonologia: uma discussão a partir da complexidade. Revista do GEL, v. 17, n. 1, p. 107-123, 2020. Disponível em: https://revistas.gel.org.br/rg

DOI: http://dx.doi.org/10.21165/gel.v17i1.2277

Submetido em: 28/09/2018 | Aceito em: 12/05/2020. 